\title{
Analysis of ZAP70 expression in adult acute lymphoblastic leukaemia by real time quantitative PCR
}

\author{
Geothy Chakupurakal ${ }^{1 *}$, Andrew Bell ${ }^{1}$, Mike Griffiths ${ }^{1,2}$, Farooq Wandroo ${ }^{3}$ and Paul Moss ${ }^{1}$
}

\begin{abstract}
Background: ZAP70 gene expression is associated with poor prognosis in B-cell lymphoproliferative disorders especially chronic lymphocytic leukaemia (CLL) but its role in adult B-ALL has not been established. On diagnostic samples from 76 patients with adult ALL (65 with B-ALL and 11 with T-ALL) ZAP70 mRNA expression levels were studied by real time-quantitative PCR (RT-qPCR) analysis.

Findings: A broad distribution of ZAP70 expression was observed in ALL, ranging from 0.002 to 5.3 fold that of the ZAP70 positive Jurkat reference cell line. No association was observed between expression levels and the presence of specific cytogenetic abnormalities. Five cases, including one case of T-ALL, had ZAP70 expression above the level of the Jurkat reference cell line.

Conclusions: Our results confirm the frequent expression of ZAP70 in adult ALL. Limited comparisons made did highlight poor-risk patients with high ZAP70 expression, but due to lack of clinical information on patient samples we were unable to directly assess the impact on disease prognosis. ZAP-70 may be an important laboratory assay in adult ALL and further studies are warranted to study a potential correlation with cytogenetic and other genetic markers.
\end{abstract}

Keywords: ZAP70, ALL, RT-qPCR

\section{Background}

Zeta associated protein tyrosine kinase $(Z A P 70)$ is a $70 \mathrm{kD}$ molecule associated with the $\zeta$-chain of the CD3 T-cell receptor (TCR) complex [1]. On formation of the immunological synapse, immune receptor tyrosine-based activation motifs (ITAM) in the CD3 and $\zeta$-chains are activated by phosphorylation. The $\zeta$-chains become docking sites for ZAP70 thereby activating the MAP kinase, calcium/calcineurin and protein kinase $C$ signalling pathways. Thus ZAP70 plays a major part in lymphocyte signal transduction resulting in cell differentiation and proliferation [2].

ZAP70 gene expression plays a critical role in the transition of pre-B to pro-B cells within the bone marrow. Genetic inactivation of the ZAP70 gene results in failure of pre-B cell receptor (pre-BCR) induced differentiation, proliferation and heavy chain exclusion, and a failure to

\footnotetext{
* Correspondence: geothy@doctors.org.uk

'School of Cancer Sciences, University of Birmingham, Birmingham UK

Full list of author information is available at the end of the article
}

progress beyond the pre-B cell stage [3]. ZAP70 is not expressed in normal mature $B$ cells derived from bone marrow, peripheral blood, or tonsil [4]. ZAP70 expression is also observed in a large proportion of patients with chronic lymphocytic leukaemia (CLL) where it has been associated with poor clinical outcome in several studies [5]. More recently, ZAP70 protein has been detected in a wide variety of additional B-cell lymphoproliferative disorders including mantle cell lymphoma, diffuse large B-cell lymphoma, and Burkitt lymphoma [6,7].

While several groups, including our own, have demonstrated ZAP70 mRNA expression in paediatric pre-B ALL [8], there have been no previous studies that have used RT-qPCR to determine ZAP70 expression in adult cases of ALL and then correlated the results with cytogenetic abnormalities at diagnosis. In the present work we have used RT-qPCR analysis to determine the expression of ZAP70 mRNA levels in 76 adult patients with B-ALL or T-ALL at the time of diagnosis. We show that ZAP70 gene expression is detected in almost all cases with a broad range of 
expression levels across the cohort. No association was observed between ZAP70 expression and cytogenetic abnormalities identified in these patients.

\section{Results}

In total we examined 76 cases of ALL, of which 65 were of B-cell origin (B-ALL) and 11 of T-cell origin (T-ALL). ZAP70 mRNA expression was measured as fold increase/decrease relative to expression levels in the reference ZAP70 positive Jurkat cell line Table 1 . A broad range of distribution of ZAP70 mRNA expression (range 0.002-5.36; median 0.169; mean 0.306) (Figure 1a) was observed. As expected, ZAP70 expression was seen in all cases of T-ALL (range 0.09-2.955; median 0.233; mean 0.504) (Figure 1b). Overall, 5 cases (4 B-ALL, 1 T-ALL) expressed ZAP70 at higher levels than the reference $Z A P 70$ positive Jurkat cell line (Figure $1 b$ ).

We then searched for potential correlations between ZAP70 expression and known genetic abnormalities within the B-ALL tumours. 53/65 (82\%) in the B-ALL group had cytogenetic changes such as $t(9 ; 22)(n=18), 9 p$ abnormality $(\mathrm{n}=12), \mathrm{t}(1 ; 19)$ TCF3-PBX1 gene fusion, (previously called $E 2 A-P B X 1)(\mathrm{n}=3)$ and a range of other abnormalities, including Burkitt lymphoma, hyperdiploidy, hypodiploidy, monosomy 7 and $12 \mathrm{p}$ abnormality $(\mathrm{n}=20)$. 12 cases of B-ALL had no observable cytogenetic abnormality. No association was observed between the level of ZAP70 expression and individual cytogenetic subgroups (Figure 1c), although we noted a statistically insignificant trend towards increased levels of ZAP70 mRNA in cases with monosomy 7 and $12 \mathrm{p}$ abnormalities (data not shown). No association was found between ZAP70 mRNA expression and the ZAP70 copy numbers based on cytogenetic data (Additional file 1).
While a relatively continuous distribution pattern of ZAP70 mRNA levels was seen across the B-ALL cohort, the level of expression was markedly increased in 4 cases, with values ranging from 1.1-5.4 (mean 2.4). Of these B-ALL patients, two had complex cytogenetics whilst the other two had $t(9,22)$ translocations thus predicting poor outcomes in all four cases [9]; however the remaining 16 patients who carried a $t(9 ; 22)$ cytogenetic abnormality had ZAP70 expression levels within the main distribution. Similar to CLL patients where a high ZAP70 expression level is associated with a poor prognosis, ZAP70 mRNA expression may be relevant to the prognosis of patients with B-ALL.

\section{Discussion}

This is the first distribution profile for ZAP70 mRNA expression in adult B-lineage ALL patients by RT-qPCR. The results demonstrate a broad range of expression and a markedly increased expression in a small proportion of cases (6\%). Chiaretti et al. [10] used microarray analysis to determine ZAP70 mRNA expression in 95 adult ALL cases followed by immunoblotting to confirm protein expression. In their study, relatively high $Z A P 70$ expression levels were observed in patients with the $t(1 ; 19)$ TCF3-PBX1 gene rearrangement but similar high $Z A P 70$ levels were not seen in our cohort. CDKN2A, a tumour suppressor gene on chromosome 9 , can be inactivated by deletion, mutation or methylation. Its role in B-ALL is currently under dispute and has been identified by some groups to have a prognostic role in childhood and adult ALL [11-15]. We analysed patients with $9 \mathrm{p}$ abnormalities, without $\mathrm{t}(9 ; 22)$, $\mathrm{t}(1 ; 19), \mathrm{t}(8 ; 14)$, and found no association with ZAP70 mRNA levels.

Although the biochemical basis for the correlation between ZAP70 expression and poor prognostic aggressive

Table 1 Patient demographic and cytogenetic data

\begin{tabular}{|c|c|c|c|c|c|c|}
\hline Type & Cytogenetics & Cases & M/F & $\mathrm{Age}^{\mathrm{a}}$ & ZAP70 expression ${ }^{\mathbf{b}}$ & Associated abnormalities \\
\hline T-ALL & & 11 & $6 / 5$ & $44.7 ;(19-56)$ & $0.363 ; 0.252 ;(0.090-2.955)$ & $\begin{array}{l}9 p \text { abnormality }(n=5) 6 q \text { deletion }(n=2 t(10 ; 14) \\
(n=1)\end{array}$ \\
\hline B-ALL & & 65 & $36 / 29$ & 46.0; (18-79) & $0.332 ; 0.185 ;(0.002-5.360)$ & \\
\hline B-ALL & $\mathrm{t}(9 ; 22)$ & 18 & $10 / 8$ & $44.4 ;(23-70)$ & $0.440 ; 0.191 ;(0.010-5.360)$ & $\begin{array}{l}\text { Hyperdiploid }(n=2) \text {, Monosomy } 7(n=2) 9 p \\
\text { abnormality }(n=3) 12 p \text { gain }(n=2) t(1 ; 19)(n=1)\end{array}$ \\
\hline B-ALL & $\mathrm{t}(1 ; 19) T C F 3-P B X 1$ & 3 & $2 / 1$ & $43.3 ;(42-52)$ & $0.219 ; 0.210 ;(0.193-0.254)$ & $9 p$ abnormality $(n=2) 6 q$ deletion $(n=2)$ \\
\hline$B-A L L$ & $9 p$ abnormality & 12 & $8 / 4$ & $45.2 ;(18-72)$ & $0.180 ; 0.176 ;(0.004-0.535)$ & $\begin{array}{l}\text { Monosomy7 }(n=2) \text { RUNX1 }(n=2) 12 p \\
\text { abnormality }(n=3) 6 q \text { deletion }(n=2)\end{array}$ \\
\hline B-ALL & Burkitt lymphoma & 6 & $3 / 3$ & $44.7 ;(22-78)$ & $0.159 ; 0.168 ;(0.005-0.350)$ & $12 p$ abnormality $(n=1) 9 p$ abnormality $(n=2)$ \\
\hline B-ALL & Hyperdiploid & 6 & $5 / 1$ & $45.9 ;(22-76)$ & $0.232 ; 0.184 ;(0.004-1.383)$ & \\
\hline B-ALL & Monosomy 7 & 4 & $1 / 3$ & $44.9 ;(37-58)$ & $0.177 ; 0.182 ;(0.015-0.399)$ & $12 \mathrm{p}$ abnormality $(\mathrm{n}=1)$ \\
\hline B-ALL & Hypodiploid & 3 & $1 / 2$ & $43.7 ;(18-79)$ & $0.173 ; 0.182 ;(0.067-0.290)$ & $12 \mathrm{p}$ abnormality $(\mathrm{n}=1)$ \\
\hline$B-A L L$ & MLL/AFF1 & 1 & 1 & 30.0 & 0.089 & 12p abnormality \\
\hline B-ALL & Normal $46, X X$ or $46, X Y$ & 12 & $6 / 6$ & $46.7 ;(18-82)$ & $0.140 ; 0.100 ;(0.002-0.291)$ & \\
\hline
\end{tabular}



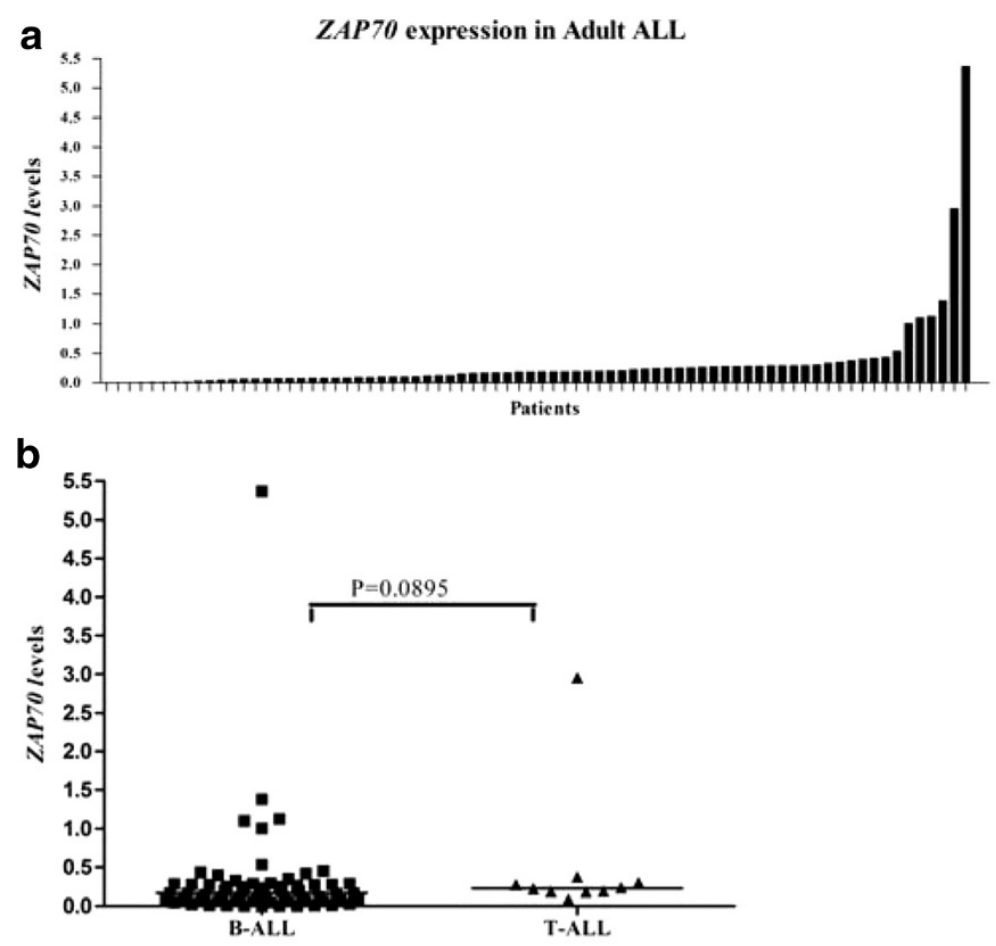

C

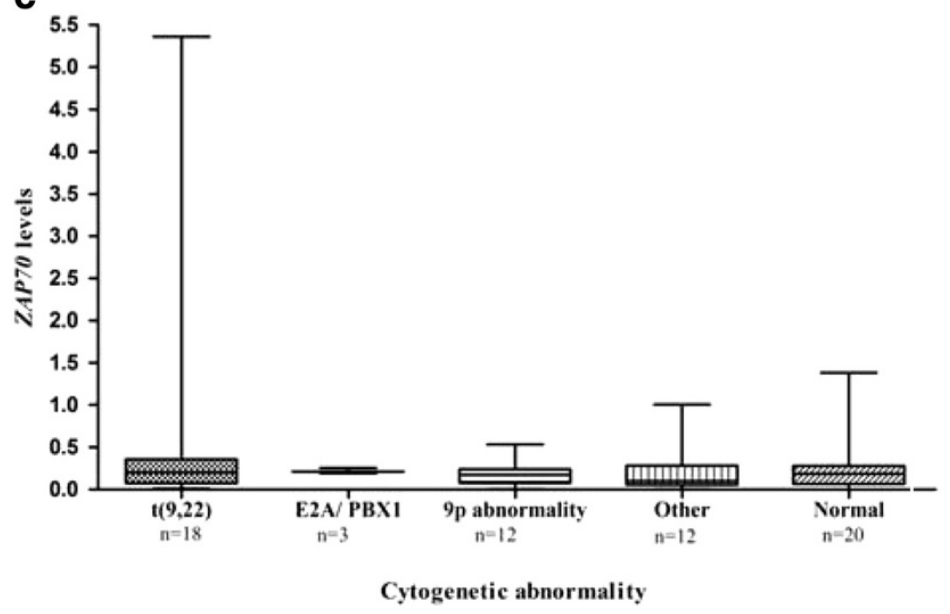

Figure 1 ZAP70expression in adult ALL patients. (a) ZAP70 RNA expression in adult ALL patients quantified by RT-qPCR. (b) ZAP70 expression in combined adult B-ALL and T-ALL patient cohorts. (c) ZAP70 expression in adult B-ALL patients classified into different cytogenetic groups. The cytogenetic group classified as others includes Burkitt lymphoma, hyperdiploid, hypodiploid, monosomy 7 and MLL/AFF1. In each panel, ZAP70 mRNA levels were normalised to GAPDH expression and then reported as a fold increase/decrease relative to ZAP70 expression in the Jurkat cell line (set as an arbitrary value of 1.0$) ; n=$ number of patients.

disease in CLL is unknown, an association with enhanced signal transduction through the pre-BCR complex and phosphorylation of phosphotyrosine phosphatase has been observed [16]. Unfortunately clinical information on patients recruited into this study could not be obtained, though the cytogenetic information on patients with high ZAP70 mRNA levels suggests possible inferior outcomes. This potential association of high ZAP70 mRNA levels with inferior outcomes may not be independent, as the cytogenetic findings in the four patients with the highest ZAP70 expression, i.e. complex or $\mathrm{t}(9 ; 22)$, also predict a poor prognosis. However cytogenetic assessment can be difficult [17] and therefore ZAP70 mRNA expression levels may have a role as an alternative prognostic marker in patients with adult BALL. This in turn may allow escalation or de-escalation of therapeutic strategies as well as the possibility of using the ZAP70-specific inhibitor, Piceatannol [18] as an 
adjuvant in ALL therapy. Large cohort studies in adult ALL patients addressing the role of ZAP70 mRNA expression levels in association with cytogenetic and other genetic markers are hence warranted.

\section{Methods}

\section{Patient samples}

Bone marrow specimens were collected at disease presentation from adult ALL patients attending various centres in West Midlands, UK and referred to the West Midlands Regional Genetics Laboratory between 1998 and 2005, as part of routine genetic analysis of the leukaemias. Bone marrow mononuclear cells (BMMC) were isolated either by Ficoll density centrifugation or by red cell lysis using Erythrocyte Lysis Buffer (Qiagen, Crawley, UK). BMMC were lysed and total RNA was recovered in $60 \mu \mathrm{l}$ RNAse free water using QIAamp spin columns (QIAamp RNA Blood Mini Kit, Qiagen, Crawley, UK). Excess material after diagnostic testing was stored within the ethically approved Central England Haemato-oncology Research Biobank (REC reference: 09/H0405/12). Anonymised cDNA samples from the biobank were used for the ZAP70 study. Samples included in the study were from consecutive cases where sufficient excess material remained in patients older than 16 .

\section{Routine cytogenetics, FISH and endpoint RT-PCR}

Cytogenetic analysis was performed as part of routine analysis using standard methods (G-banding). FISH analysis for MLL rearrangements, BCR-ABL1 gene fusions, and ETV6RUNX1 gene fusion was routinely performed on all ALL samples [17], using commercial probes following manufacturer's protocols (Vysis LSI MLL Dual Color, Break Apart Rearrangement Probe; Vysis LSI BCR/ABL Dual Color, Dual Fusion Translocation Probe; Vysis LSI ETV6(TEL)/ RUNX1(AML1) ES Dual Color Translocation Probe Set) (Abbott Molecular, Illinois, USA). In addition, other FISH probes were used variably due to suspicion on G-band analysis and changes in routine FISH screening policies during the period when the samples were collected (Vysis LSI p16 (9p21) SpectrumOrange/CEP 9 SpectrumGreen Probe; MYC Break Apart FISH Probe Kit; IGH/MYC/CEP 8 TriColor DF FISH Probe Kit; LSI IGH Dual Color, Break Apart Rearrangement Probe; CEP4 and CEP10 probes (Abbott Molecular, Illinois, USA); and Dako SIL-TAL1 FISH DNA Probe, Sub-Deletion Signal (Dako, Glostrup, Denmark)). End-point RT-PCR for BCR-ABL1 transcripts was performed routinely using standard procedures [19].

\section{Quantification of ZAP70 expression by RT-qPCR}

Relative quantitation of ZAP70 mRNA expression was performed using an ABI 7700 Sequence Detection System (Applied Biosystems UK) and analysed using SDS software 1.7. ZAP70 transcripts were detected using the following primers and probe: forward primer 5'-CGCTGCACAA
GTTCCTGGT-3', reverse primer 5'-GACACCTGGT GCAGCAGCT-3', Taqman probe 5'-(FAM)-CATTGC TCACAGGGATCTCCTCCCTCT-(TAMRA)-3'. GAPDH transcripts, which served as an internal control, were quantified using a commercial assay (Applied Biosystems, U.K.). PCR amplification and data normalisation were performed as previously described [8]. These normalised ZAP70 to GAPDH ratios were then calculated as a fold change relative to the $Z A P 70$ to GAPDH ratio of the ZAP70 positive Jurkat T-cell line, defined as having an expression level of 1.0. All test samples were run in duplicate (mean values used) and template-negative samples served as control and were always negative.

\section{Statistical analysis}

Statistical analysis was performed by group comparison using either a two-sample test or ANOVA and correlation analysis was evaluated with Pearson coefficient, using GraphPad Prism 4 and SPSS software.

\section{Additional file}

Additional file 1: Table S1. ZAP70 expression data and cytogenetic analysis of individual ALL samples.

List of abbreviations

ALL: Acute lymphoblastic leukaemia; CLL: Chronic lymphocytic leukaemia; ZAP70: Zeta associated protein70.

Competing interests

The authors declare no competing interests.

Acknowledgements

This work was funded by the Medical Research Council.

\section{Author details}

${ }^{1}$ School of Cancer Sciences, University of Birmingham, Birmingham UK. ${ }^{2}$ West Midlands Regional Genetics Laboratory, Birmingham Women's NHS Foundation Trust, Birmingham B15 2TG, UK. ${ }^{3}$ Sandwell and West Birmingham Hospitals NHS Trust, Birmingham B18 7QH, UK.

\section{Author's contributions}

PM and MG conceived and co-ordinated the study. GC and $A B$ carried out molecular genetic studies. GC, AB and MG analysed the data. GC drafted the manuscript. PM, MG and FW participated in study design and helped in drafting the manuscript. All authors read and approved the final manuscript.

Received: 12 February 2012 Accepted: 17 April 2012

Published: 1 May 2012

\section{References}

1. Dickinson JD, Gilmore J, labal J, Sanger W, Lynch JC, Chan J, Bierman PJ, Joshi SS: 11q22.3 deletion in B-chronic lymphocytic leukemia is specifically associated with bulky lymphadenopathy and ZAP-70 expression but not reduced expression of adhesion/cell surface receptor molecules. Leuk Lymphoma 2006, 47(2):231-244.

2. Weiss A, Chan AC, Iwashima M, Straus D, Irving BA: Regulation of protein tyrosine kinase activation by the T-cell antigen receptor zeta chain. Cold Spring Harb Symp Quant Biol 1992, 57:107-116.

3. Schweighoffer E, Vanes L, Mathiot A, Nakamura T, Tybulewicz VL: Unexpected requirement for ZAP-70 in pre-B cell development and allelic exclusion. Immunity 2003, 18(4):523-533.

4. Crespo M, Villamor N, Gine E, Muntanola A, Colomer D, Marafioti T, Jones M, Camos M, Campo E, Montserrat E, et al: ZAP-70 expression in normal pro/ 
pre B cells, mature B cells, and in B-cell acute lymphoblastic leukemia. Clin Cancer Res 2006, 12 (3 Pt 1):726-734.

5. Crespo M, Bosch F, Villamor N, Bellosillo B, Colomer D, Rozman M, Marce S, Lopez-Guillermo A, Campo E, Montserrat E: ZAP-70 expression as a surrogate for immunoglobulin-variable-region mutations in chronic lymphocytic leukemia. N Engl J Med 2003, 348(18):1764-1775.

6. Admirand JH, Rassidakis GZ, Abruzzo LV, Valbuena JR, Jones D, Medeiros $L$ : Immunohistochemical detection of ZAP-70 in 341 cases of non-Hodgkin and Hodgkin lymphoma. Mod Pathol 2004, 17(8):954-961.

7. Carreras J, Villamor N, Colomo L, Moreno C, Ramon Y, Cajal S, Crespo M, Tort F, Bosch F, Lopez-Guillermo A, Colomer D, et al: Immunohistochemical analysis of ZAP-70 expression in B-cell lymphoid neoplasms. J Pathol 2005, 205(4):507-513.

8. Wandroo F, Bell A, Darbyshire P, Pratt G, Stankovic T, Gordon J, Lawson S, Moss P: ZAP-70 is highly expressed in most cases of childhood pre-B cell acute lymphoblastic leukemia. Int I Lab Hematol 2008, 30(2):149-157.

9. Gokbuget N, Hoelzer D: Treatment of adult acute lymphoblastic leukemia. Semin Hematol 2009, 46(1):64-75.

10. Chiaretti S, Guarini A, De Propris MS, Tavolaro S, Intoppa S, Vitale A, lacobelli S, Elia L, Ariola C, Ritz J, et al: ZAP-70 expression in acute lymphoblastic leukemia: association with the E2A/PBX1 rearrangement and the pre-B stage of differentiation and prognostic implications. Blood 2006, 107(1):197-204.

11. Kim M, Yim SH, Cho NS, Kang SH, Ko DH, Oh B, Kim TY, Min HJ, She CJ, Kang $\mathrm{HJ}$, et al: Homozygous deletion of CDKN2A (p16, p14) and CDKN2B (p15) genes is a poor prognostic factor in adult but not in childhood Blineage acute lymphoblastic leukemia: a comparative deletion and hypermethylation study. Cancer Genet Cytogenet 2009, 195(1):59-65.

12. Hann I, Vora A, Harrison G, Harrison C, Eden O, Hill F, Gibson B, Richards S: Determinants of outcome after intensified therapy of childhood lymphoblastic leukaemia: results from Medical Research Council United Kingdom acute lymphoblastic leukaemia XI protocol. Br J Haematol 2001, 113(1):103-114.

13. Mirebeau D, Acquaviva C, Suciu S, Bertin R, Dastugue N, Robert A, Boutard P, Mechinaud F, Plouvier E, Otten J, et al: The prognostic significance of CDKN2A, CDKN2B and MTAP inactivation in B-lineage acute lymphoblastic leukemia of childhood. Results of the EORTC studies 58881 and 58951. Haematologica 2006, 91(7):881-885.

14. Moorman AV, Harrison CJ, Buck GA, Richards SM, Secker-Walker LM, Martineau M, Vance GH, Cherry AM, Higgins RR, Fielding AK, et al: Karyotype is an independent prognostic factor in adult acute lymphoblastic leukemia (ALL): analysis of cytogenetic data from patients treated on the Medical Research Council (MRC) UKALLXII/Eastern Cooperative Oncology Group (ECOG) 2993 trial. Blood 2007, 109(8):3189-3197.

15. Sulong S, Moorman AV, Irving JA, Strefford JC, Konn ZJ, Case MC, Minto L, Barber KE, Parker $\mathrm{H}$, Wright SL, et al: A comprehensive analysis of the CDKN2A gene in childhood acute lymphoblastic leukemia reveals genomic deletion, copy number neutral loss of heterozygosity, and association with specific cytogenetic subgroups. Blood 2009, 113(1):100-107.

16. Chen Z, Aston E, Yu MK: Loss of Zap-70 and low molecular weight phosphotyrosine phosphatase occurs after therapy in a patient with Bchronic lymphocytic leukemia. Leukemia 2005, 19(8):1503-1505.

17. Harrison CJ, Moorman AV, Barber KE, Broadfield ZJ, Cheung KL, Harris RL, Jalali GR, Robinson HM, Strefford JC, Stewart A, et al: Interphase molecular cytogenetic screening for chromosomal abnormalities of prognostic significance in childhood acute lymphoblastic leukaemia: a UK Cancer Cytogenetics Group Study. Br J Haematol 2005, 129(4):520-530.

18. Fernandez $L A$, Torrealba J, Yagci G, Ishido N, Tsuchida M, Tae Kim H, Dong Y, Oberley T, Fechner J, Colburn MJ, et al: Piceatannol in combination with low doses of cyclosporine A prolongs kidney allograft survival in a stringent rat transplantation model. Transplantation 2002, 74(11):1609-1617.

19. Mason J, Griffiths M: Detection of minimal residual disease in leukaemia by RT-PCR. Methods Mol Biol 2011, 688:269-280.

doi:10.1186/1755-8166-5-22

Cite this article as: Chakupurakal et al: Analysis of ZAP70 expression in adult acute lymphoblastic leukaemia by real time quantitative PCR. Molecular Cytogenetics 2012 5:22.

\section{Submit your next manuscript to BioMed Central and take full advantage of:}

- Convenient online submission

- Thorough peer review

- No space constraints or color figure charges

- Immediate publication on acceptance

- Inclusion in PubMed, CAS, Scopus and Google Scholar

- Research which is freely available for redistribution 